\title{
AKTIVITAS EKSTRAK DAUN BANGUN-BANGUN (COLEUS AMBOINICUS LOUR) SEBAGAI ANTIINFLAMASI PADA TIKUS PUTIH (RATTUS NORVEGICUS)
}

\author{
Dise Rahmawati ${ }^{1{ }^{*},}$, Riski Sulistiarini ${ }^{1}$, Muhammad Amir Masruhim ${ }^{2}$ \\ ${ }^{1}$ Laboratorium Penelitian dan Pengembangan Kefarmasian "Farmaka Tropis", \\ Fakultas Farmasi, Universitas Mulawarman, Samarinda \\ *Email :dise.imud@gmail.com \\ ${ }^{2}$ Program Studi Pendidikan Kimia, Fakultas Keguruan dan Ilmu Pendidikan, \\ Universitas Mulawarman, Samarinda
}

\begin{abstract}
ABSTRAK
Penelitian ini bertujuan untuk mengetahui kandungan metabolit sekunder pada daun bangun-bangun dan aktivitas ekstrak daun bangun-bangun sebagai antiinflamasi. Hasil pengujian metabolit sekunder menunjukkan bahwa daun bangun-bangun mengandung flavonoid, saponin, steroid dan triterpenoid. Sedangkan metode yang digunakan yaitu induksi karagenan pada kaki tikus putih. Tikus putih dikelompokkan menjadi lima kelompok yaitu kelompok kontrol negatif yang diberi $\mathrm{Na} \mathrm{CMC}$, kelompok kontrol positif yang diberi Na diklofenak dengan dosis $50 \mathrm{mg}$ dan tiga kelompok uji yang diberikan ekstrak dengan tiga variasi dosis yaitu 150 $\mathrm{mg} / 200 \mathrm{gBB}$ tikus, $200 \mathrm{mg} / 200 \mathrm{gBB}$ tikus dan $250 \mathrm{mg} / 200 \mathrm{gBB}$ tikus yang masingmasing diberikan oral serta tiap tikus dikondisikan bengkak terlebih dahulu pada kaki tikus. Pengukuran bengkak pada kaki tikus dengan mengukur diameter kaki tikus terlebih dahulu dengan plestimometer. Dari hasil pengukuran menunjukkan dosis $250 \mathrm{mg} / 200 \mathrm{gBB}$ memiliki aktivitas penurunan radang lebih baik dari dosis lainnya.
\end{abstract}

Kata kunci : Coleuss amboinicus Lour., Antiinflamasi, Tikus Putih.

\begin{abstract}
This study aims to determine the content of secondary metabolites in leaf shapes and leaf extract activity as anti-inflammatory wake. The test results showed that the secondary metabolites of leaves wake contains flavonoids, saponins, steroids and triterpenoids. While the method used is the induction of carrageenan on foot white rat. White rat were grouped into five groups: negative control group that was given $\mathrm{Na} \mathrm{CMC}$, the positive control group were given $\mathrm{Na}$ diclofenac $50 \mathrm{mg}$ and three test groups were given the extract with three variations of doses of $150 \mathrm{mg} / 200 \mathrm{gBB}$ rat,
\end{abstract}

Samarinda, 5-6 Juni 2015 
$200 \mathrm{mg} / 200 \mathrm{gBB}$ rat and $250 \mathrm{mg} / 200 \mathrm{gBB}$ rat, respectively and each rat was given oral conditioned beforehand swelling in the legs of rat. Measurement of swelling in the legs of rat by measuring the diameter of rat feet first with plestimometer. From the measurement results indicate a dose of $250 \mathrm{mg} / 200 \mathrm{gBB}$ had a decrease in inflammatory activity is better than the other doses.

Keywords: Teak Leaves, Anti-inflammatory, Coleus amboinicus L, Rattus norvegicus.

\section{PENDAHULUAN}

Indonesia merupakan negara yang memiliki banyak keanekaragaman baik habitat, maupun flora dan faunanya. Keanekaragaman ini pula yang membuat Indonesia memiliki banyak keanekaragaman hayati terutama dalam tanaman tradisional salah satunya adalah tumbuhan bangun-bangun. Tumbuhan bangunbangun merupakan tumbuhan yang biasa digunakan oleh masyarakat kutai untuk mengobati demam, sariawan dan reumatik.

Banyak masyarakat yang menganggap tumbuhan bangun-bangun adalah tumbuhan yang mengganggu sehingga belum banyak penelitian lebih lanjut tentang manfaat dari tumbuhan bangun-bangun tersebut terutama pada manfaat tumbuhan bangun-bangun sebagai antiinflamasi. Hasil skrining fitokimia menjelaskan bahwa tumbuhan bangun-bangun (Coleus amboinicus L.) memiliki metabolit sekunder pada beberapa bagian tumbuhan terutama pada akar dan daunnya. Pada bagian daun mengandung flavonoid, saponin, steroid dan triterpenoid [1], dimana flavonoid dan saponin merupakan senyawa yang memiliki aktivitas sebagai antiinflamasi [2].

Berdasarkan uraian di atas, telah dilakukan penelitian yang terdiri dari skrining fitokimia untuk mengindetifikasi kandungan senyawa metabolit sekunder serta uji aktivitas antiinflamasi ekstrak daun Bangun-bangun pada Tikus putih.

\section{METODE PENELITIAN}

\section{Bahan}

Bahan yang diteliti adalah daun bangun-bangun, pelarut etanol $70 \%, \mathrm{NaCl}$ $0,9 \%$, karagenan, aquadest, $\mathrm{Na}$ dikofenak, $\mathrm{Na} \mathrm{CMC}$, pita magnesium, asam klorida ( $\mathrm{HCl})$, besi (III) klorida, asam asetat anhidrat, $\mathrm{H}_{2} \mathrm{SO}_{4}$ dan kloroform.

\section{Peralatan}

Peralatan yang digunakan dalam penelitian ini antara lain timbangan digital, seperangkat alat ekstraksi, labu ukur, batang pengaduk, rotary evaporator, water bath, tabung reaksi, pipet tetes, pipet volume, inkubator, pletismometer, spoid dan sonde serta alat penunjang lainnya. 


\section{Pengambilan Sampel}

Tumbuhan yang digunakan pada penelitian ini adalah bangun-bangun yang berasal dari Tenggarong, Kutai Kartanegara. Bagian tanaman yang digunakan adalah bagian daun yang masih segar. Sampel yang telah terkumpul dicuci bersih selanjutnya dilakukan sortasi basah. Pengeringan dilakukan untuk mengurangi kadar air dengan cara dianginkan. Selanjutnya disortasi kering untuk memilih sampel yang telah kering bebas dari kotoran dan kerusakan. Setelah itu dilakukan perajangan untuk memperluas permukaan daun bangun-bangun kontak dengan pelarut dengan simplisia.

\section{Prosedur Ekstraksi}

Simplisia dimasukkan ke dalam bejana maserasi dan dimaserasi menggunakan pelarut etanol $70 \%$. Proses ekstraksi dengan metode maserasi berlangsung selama kurang lebih 3 hari. Maserat (hasil maserasi) disaring menggunakan kertas saring dan ditampung ke dalam wadah. Maserat kemudian dipekatkan menggunakan rotary evaporator dan dilanjutkan dengan penguapan di atas waterbath hingga diperoleh ekstrak etanol kental.

\section{Prosedur Pengujian}

\section{Pengujian Metabolit Sekunder}

Identifikasi metabolit sekunder daun bangun-bangun dilakukan menggunakan ekstrak etanol dengan cara mengamati perubahan warna dan terjadinya pengendapan menggunakan reagen kimia. Golongan metabolit sekunder yang diuji adalah flavonoid, saponin, serta steroid dan tritepenoid. Identifikasi senyawa flavonoid dengan menggunakan etanol, logam $\mathrm{Mg}$, dan $\mathrm{HCl}$. Identifikasi senyawa saponin dengan menambahkan aquades lalu dikocok kuat, dan ditambahkan $\mathrm{HCl}$. Identifikasi senyawa steroid dan triterpenoid dengan menggunakan asam asetat anhidrat, kloroform dan asam sulfat pekat. Metabolit sekunder daun bangun-bangun dianalisis dengan cara tabulasi jika terdapat metabolit sekunder setelah penambahan reagen kimia tertentu diberi tanda positif $(+)$ dan jika tidak terdapat metabolit sekunder diberi tanda negatif (-).

\section{Pengujian Antiinflamasi}

Tikus dikelompokkan ke dalam 5 kelompok, yaitu kelompok kontrol negat if (Na CMC), kelompok kontrol positif (Na Diklofenak dosis $50 \mathrm{mg}$ ), dan kelompok bahan uji (Dosis 150mg/200gBB tikus, Dosis 200mg/200gBB tikus, dan Dosis $250 \mathrm{mg} / 200 \mathrm{gBB}$ tikus ekstrak etanol daun Bangun-bangun). Tikus putih yang telah dipersiapkan untuk penelitian akan dipuasakan dari makanan selama 18 jam dengan tetap diberi air minum.

Sebelum pengujian, masing-masing hewan ditimbang berat badannya, pada saat pengujian masing-masing hewan uji diberi tanda pada kaki kirinya, kemudian kaki kiri tikus dimasukkan ke dalam bejana pletismometer yang berisi NaCL 0,9\% sampai tanda batas garis skala pengukur pletismometer, dicatat angka pada monitor pletismometer sebagai volume awal (Vo) yaitu volume kaki sebelum diinduksi dengan larutan karagenan. Masing-masing tikus diberi suspensi bahan uji secara 
oral sesuai dengan kelompoknya. Kemudian telapak kaki kiri tikus disuntik secara intraplantar dengan $0,1 \mathrm{ml}$ larutan karagenan $1 \%$. Setelah 1 jam, dilakukan pengukuran dengan cara mencelupkan kaki tikus ke dalam bejana pletismometer yang berisi $\mathrm{NaCL} 0,9 \%$ sampai mencapai batas garis skala pletismometer. Perubahan volume cairan yang terjadi dicatat sebagai volume telapak kaki tikus. Pengukuran dilakukan setiap 1 jam selama 6 jam.

\section{HASIL DAN PEMBAHASAN}

\section{Metabolit Sekunder Ekstrak Etanol Daun Bangun-Bangun}

Senyawa metabolit sekunder merupakan produk alami atau senyawa alam yang eksistensinya tidak begitu penting dalam tubuh tetapi berperan penting pada kelangsungan hidup suatu makhluk hidup. Sebagian besar tanaman penghasil senyawa metabolit sekunder memanfaatkan senyawa tersebut untuk mempertahankan diri dan berkompetisi dengan makhluk hidup lain di sekitarnya. Hasil identifikasi metabolit sekunder ekstrak daun Bangun-bangun dapat dilihat pada Tabel 1.

Tabel 1 Identifikasi Metabolit Sekunder Ekstrak Daun Bangun-Bangun

\begin{tabular}{cc}
\hline \multirow{2}{*}{ Metabolit Sekunder } & Perlakuan \\
\cline { 2 - 2 } Flavonoid & + \\
Saponin & + \\
Steroid & + \\
Triterpenoid & + \\
\hline
\end{tabular}

Keterangan: Data berupa data kualitatif (-) dan (+), dimana:

$(-)$ : Tidak teridentifikasi metabolit sekunder

$(+)$ : Teridentifikasi metabolit sekunder.

Berdasarkan hasil identifikasi metabolit sekunder pada Tabel di atas menunjukan bahwa ekstrak daun bangun-bangun mengandung golongan metabolit sekunder flavanoid, saponin, steroid dan triterpenoid.

Uji flavonoid menggunakan pereaksi pita $\mathrm{Mg}$ dan $\mathrm{HCl}$. Hasil uji menunjukkan teridentifikasinya golongan senyawa flavanoid pada ekstrak etanol daun bangun-bangun yang ditunjukan dengan terbentuknya kompleks jingga. Identifikasi saponin pada ekstrak etanol daun bangun-bangun menunjukan bahwa senyawa saponin teridentifikasi pada ekstrak daun bangun-bangun yang ditunjukkan dengan terjadi pembentukkan buih yang stabil pada saat ekstrak dikocok dan didiamkan 15 menit (setelah itu ditambahkan $\mathrm{HCl}$ ). Uji senyawa golongan terpenoid menggunakan pereaksi kloroform, asam asetat anhidrat dan $\mathrm{H}_{2} \mathrm{SO}_{4}$. Hasil uji metabolit sekunder menunjukkan teridentifikasinya senyawa golongan steroid dan triterpenoid pada ekstrak etanol daun bangun-bangun yang 
ditunjukkan dengan terbentuknya larutan berwarna hijau dan cincin merah kecoklatan.

\section{Aktivitas Antiinflamasi Ekstrak Daun Bangun-Bangun}

Pengujian aktivitas antiinflamasi ekstrak daun bangun-bangun merupakan suatu usaha untuk mengetahui kemampuan ekstrak daun bangun-bangun dalam meredam dan menyembuhkan inflamasi dengan melihat penurunan volume radang yang diukur terhadap tingkatan variasi dosis yang digunakan. Hasil pengujian yang menggunakan $\mathrm{Na}$ CMC $1 \%$ sebagai kontrol negatif, dan variasi dosis ekstrak etanol daun Bangun-Bangun dapat dilihat pada tabel 2.

Tabel 2 Hasil Pengujian Aktivitas Antiinflamasi Ekstrak Daun Bangun-Bangun

\begin{tabular}{cccccccc}
\hline \multirow{2}{*}{ Perlakuan } & \multicolumn{6}{c}{ Volume kaki tikus putih $(\mathrm{mL})$ pada } & waktu t (menit) \\
\cline { 2 - 7 } & 0 & 60 & 120 & 180 & 240 & 300 & 360 \\
\hline Kontrol negatif & 0 & 1,91 & 2 & 2,09 & 2,17 & 2,28 & 2,24 \\
Dosis $150 \mathrm{mg} / 200 \mathrm{gBB}$ & 0 & 1,83 & 1,8 & 1,77 & 1,75 & 1,74 & 1,7 \\
Dosis 200 mg/200gBB & 0 & 1,76 & 1,85 & 1,93 & 1,83 & 1,71 & 1,7 \\
Dosis 250 mg/200gBB & 0 & 1,76 & 1,88 & 1,98 & 1,89 & 1,81 & 1,77 \\
Kontrol Positif & 0 & 2,15 & 2,24 & 2,33 & 2,2 & 2,17 & 2,14 \\
\hline
\end{tabular}

Jika hal tersebut disajikan dalam bentuk grafik, maka hasil dapat dilihat pada gambar 1 .

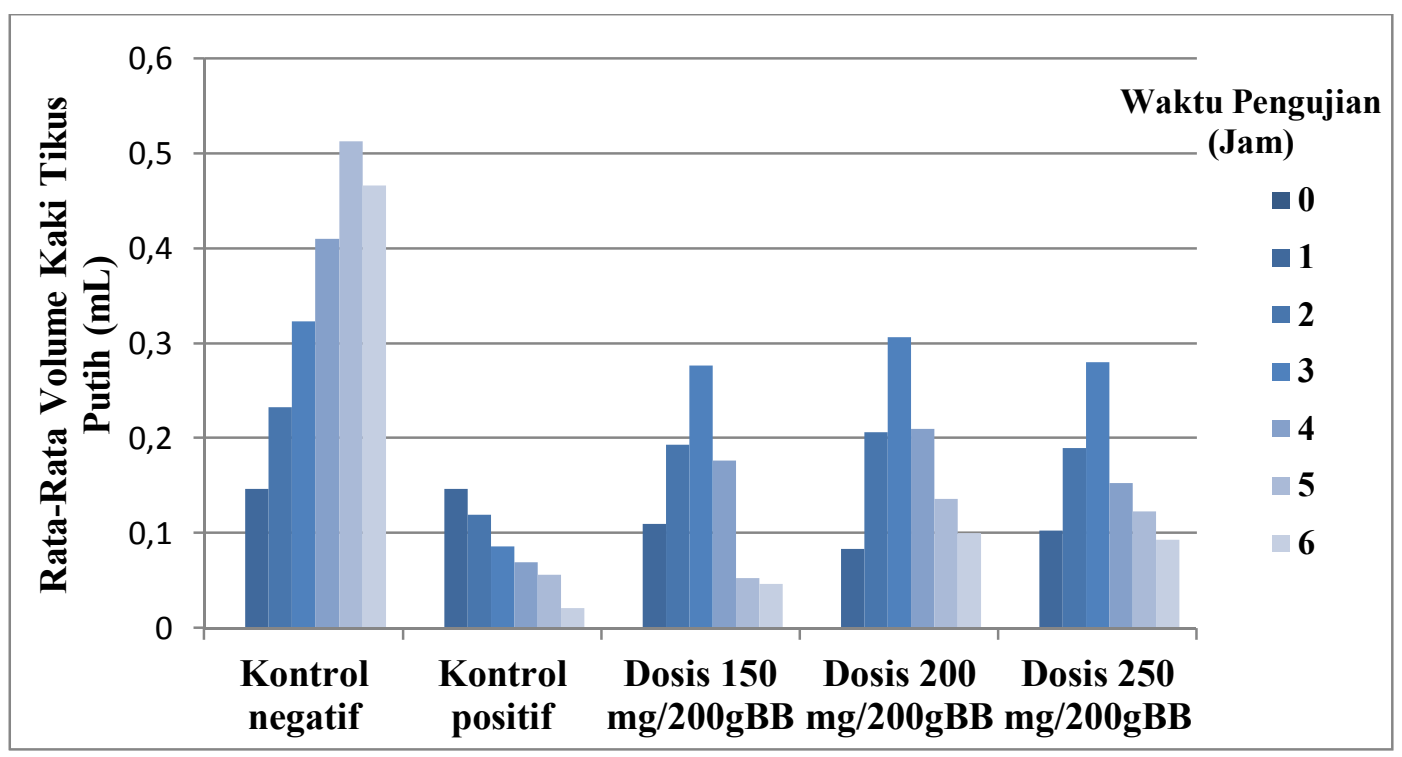

Gambar 1 Grafik Aktivitas Antiinflamasi Ekstrak Daun Bangun-Bangun 
Pada gambar 1 terlihat bahwa kontrol negatif yang menggunakan $\mathrm{Na} \mathrm{CMC}$ $1 \%$ mengalami peningkatan radang pada waktu 60 menit serta puncaknya pada waktu 300 menit. Kontrol negatif mulai mengalami penurunan volume radang pada waktu 360 menit. Perlakuan pemberian variasi dosis ekstrak daun bangun-bangun yaitu dosis $150 \mathrm{mg} / 200 \mathrm{gBB}$ tikus, $200 \mathrm{mg} / 200 \mathrm{gBB}$ tikus, dan $250 \mathrm{mg} / 200 \mathrm{gBB}$ tikus menunjukan aktivitas yang berbeda dari kontrol negatif dimana dosis ekstrak daun bangun-bangun terlihat mampu meredam dan menurunkan volume radang pada waktu yang lebih cepat dari kontrol negatif. Kontrol negatif memperlihatkan adanya peningkatan peradangan dimulai pada waktu 60 menit dan baru mengalami penurunan pada waktu 360 menit. Hal ini membuktikan bahwa pemberian Na CMC pada perlakuan kontrol negatif tidak memberikan efek peredaman dan penurunan radang dikarenakan adanya peningkatan peradangan yang terjadi. Penggunaan $\mathrm{Na}$ $\mathrm{CMC}$ pada perlakuan kontrol negatif juga berguna untuk memastikan bahwa $\mathrm{Na}$ CMC sebagai pensuspensi ekstrak yang tidak larut air, tidak memberikan aktivitas antiinflamasi

Ekstrak etanol daun bangun-bangun mampu memberikan aktivitas antiinflamasi yang ditunjukan dengan terjadinya penurunan volume radang pada kaki tikus yang terlihat pada gambar. Dosis $150 \mathrm{mg} / 200 \mathrm{Gbb}$ tikus mengalami sedikit peningkatan peradangan, sampai pada waktu 240 menit dimana radang mulai mengalami penurunan. Aktivitas peredaman radang pada dosis 150 $\mathrm{mg} / 200 \mathrm{gBB}$ tikus kurang efektif dikarenakan pada penggunaan dosis ini volume radang masih terlalu besar walaupun tidak sebesar radang yang terjadi pada kontrol negatif. Dosis $200 \mathrm{mg} / 200 \mathrm{gBB}$ tikus mengalami penurunan radang pada waktu 240 menit. Pada dosis $200 \mathrm{mg} / 200 \mathrm{gBB}$ tikus penurunan volume radang lebih baik dibandingkan dengan dosis $150 \mathrm{mg} / 200 \mathrm{gBB}$. Dimana volume radang mendekati volume awal. Dosis $250 \mathrm{mg} / \mathrm{BB}$ tikus menunjukan penurunan volume radang yang lebih baik dan cepat dibandingkan dengan dosis lainnya, hal ini terlihat dimana pada waktu 240 menit sudah mendekati volume awal. Dosis $250 \mathrm{mg} / 200 \mathrm{gBB}$ tikus ekstrak daun bangun-bangun merupakan dosis yang lebih baik dilihat dari waktu penyembuhan radang yang lebih baik dibandingkan dengan waktu penyembuhan oleh dosis $150 \mathrm{mg} / 200 \mathrm{gBB}$ tikus, $200 \mathrm{mg} / 200 \mathrm{gBB}$ tikus, serta kontrol negatif. Namun pada dosis $250 \mathrm{mg} / 200 \mathrm{gBB}$ tikus, tidak sebaik penurunan radang pada kontrol positif dimana terlihat pada kontrol positif mengalami penurunan radang pada waktu 120 menit dan kembali pada volume awal pada waktu 360 menit.

Aktivitas antiinflamasi yang dimiliki oleh ekstrak daun bangun-bangun melalui berbagai macam variasi dosisnya disebabkan oleh metabolit sekunder yang terdapat pada ekstrak daun bangun-bangun seperti flavonoid. Flavonoid dapat menghambat terjadinya radang berhubungan dengan aktivitasnya sebagai antioksidan. Flavonoid mampu menangkap oksigen reaktif dan radikal peroksil lalu menetralkannya, menghambat oksidasi asam arakhidonat menjadi endoperoksida dan menurunkan aktivitas enzim lipoksigenase. Apabila oksidasi asam arakhidonat dapat dihambat maka tidak terbentuk oksigen reaktif yang dapat menyebabkan nyeri dan inflamasi [3]. 


\section{KESIMPULAN}

1. Kandungan metabolit sekunder yang terdapat di dalam ekstrak daun bangunbangun adalah senyawa golongan flavonoid, saponin, serta steroid dan triterpenoid

2. Dosis $250 \mathrm{mg} / 200 \mathrm{Gbb}$ merupakan dosis efektif dalam proses penyembuhan radang.

\section{DAFTAR PUSTAKA}

[1] Kaliappan, Neil. 2008. Fitokimia. UI Press: Jakarta.

[2] Widyaningrum, Herlina. 2011. Kitab Tanaman Obat Nusantara. MedPress: Yogyakarta.

[3] Nayeem. 2012. Effects of plant stages of analgesic activity of the leaves of Tectona grandis. Krupanidhi college of pharmacy, Bungalore. 